\title{
Carlos Gentile de Mello: em defesa de uma medicina institucional
}

\author{
Carlos Gentile de Mello: in defense of institutional medicine
}

Tatiana Wargas de Faria Baptista (https://orcid.org/0000-0002-3445-2027) ${ }^{1}$ Camila Furlanetti Borges (https://orcid.org/0000-0002-0418-739X) ${ }^{2}$

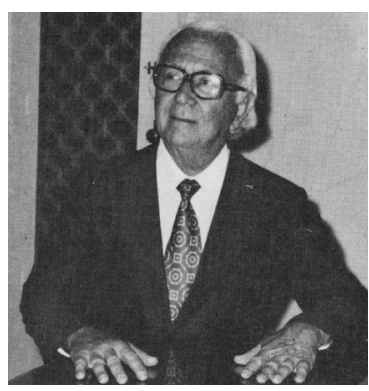

Carlos Gentile de Mello

Fonte: Acervo Casa de Oswaldo Cruz.

${ }^{1}$ Departamento de Ensino, Instituto Nacional de Saúde da Mulher, da Criança e do Adolescente, Fundação Oswaldo Cruz (Fiocruz). Av. Rui Barbosa 716, Flamengo. 22250-020 Rio de Janeiro RJ Brasil.

twargas@gmail.com

${ }^{2}$ Escola Politécnica de Saúde Joaquim Venâncio, Fiocruz. Rio de Janeiro RJ Brasil.

\begin{abstract}
The article analyzes the trajectory and thought of Carlos Gentile de Mello highlighting his contributions to the political and social debate on health between the 1960s and 1980s. He discusses the interfaces between the developmental project and health and addresses the expansion of the privatizing model especially the effects of the model on medical practice and the health of the population. The article analyzes the contribution of Gentile's analysis to the debate on Public Health and Brazilian Health Reform in the 1970s, especially on the political and institutional conditions for the project of universalization.

Key words Carlos Gentile de Mello, Health and Development, Health Policy, Public Health, Brazilian Health Reform
\end{abstract}

Resumo $O$ artigo analisa a trajetória do pensamento de Carlos Gentile de Mello ressaltando suas contribuições para o debate político e social da saúde entre os anos 1960 e 1980. Discute as interfaces entre o projeto desenvolvimentista e a saúde e aborda a expansão do modelo privatista, em especial os efeitos do modelo sobre a prática médica e a saúde da população. Tece considerações sobre as contribuições das análises de Gentile para o debate da Saúde Coletiva e da Reforma Sanitária Brasileira nos anos 1970, em especial sobre as condições politicas e institucionais para o projeto de universalização.

Palavras-chave Carlos Gentile de Mello, Saúde e Desenvolvimento, Política de Saúde, Saúde Coletiva, Reforma Sanitária Brasileira 


\section{Introdução}

Carlos Gentile de Mello talvez seja, dentre os nomeados "sanitaristas desenvolvimentistas", mais conhecido, o mais divulgado e o que parece mais ter contribuído com a discussão da Saúde Coletiva e da Reforma Sanitária nos anos 1970. Tal constatação certamente não é desprovida de uma história, de um sentido.

Gentile nasceu no primeiro quartel do século XX (1918), em Natal, Rio Grande do Norte e formou-se pela tradicional Faculdade de Medicina da Bahia no ano de 1943. No pós-guerra, a medicina iniciava importantes transformações na organização do modelo de atenção, tanto pela incorporação de novas tecnologias (novos fármacos, insumos e equipamentos), novas técnicas ${ }^{3}$, como pela difusão do modelo da História Natural da Doença (HND) e da Medicina Preventiva ${ }^{4}$.

As mudanças decorridas na organização da medicina no Brasil foram observadas por Gentile entre os anos 1940 e 1980 a partir, inicialmente de sua atuação como médico em diferentes localidades e na assistência médica previdenciária e depois como assessor no Ministério da Saúde (década de 1960), como administrador hospitalar (a partir de 1969 no Hospital de Ipanema e no Instituto Nacional do Câncer) $)^{5}$, como professor da Escola Nacional de Saúde Pública nas décadas de 1960 e 1970, e em cargos de associações médicas (Colégio Brasileiro de Cirurgiões, Associação Médica do estado do Rio de Janeiro, Associação dos Hospitais do Rio de Janeiro) $)^{6}$, onde teve atuação assumidamente política.

Nessa trajetória, observou a consolidação dos Institutos de Aposentadorias e Pensões (IAP) a partir da década de 1940 e a expansão massiva do modelo médico-previdenciário nas décadas de 1960 e $1970^{7}$. Viveu os anos do desenvolvimentismo e contribuiu na análise das relações entre saúde e desenvolvimento econômico, somando esforços ao debate sobre a importância do Estado na produção de políticas que gerassem renda e condições de vida, considerando tal aspecto condição primeira para a garantia da saúde ${ }^{8}$. Viveu os anos de autoritarismo e afirmou-se como analista atento e rigoroso dos processos de expansão da medicina previdenciária produzindo diagnósticos minuciosos sobre a organização da assistência médica no país e o crescimento do segmento empresarial da saúde - como a indústria de insumos, de medicamentos e de equipamentos, o setor de produção de serviços e o setor de formação e ensino médico -, possibilitando uma compreensão abrangente dos processos políticos e econômicos que atravessavam a definição das políticas de saúde ${ }^{9-13}$. Suas análises traziam para cena a ineficiência dos planos de saúde produzidos pelo Estado, os efeitos do modelo privatista da medicina previdenciária na prática médica e as consequências de um modelo de prestação de cuidados segmentado para a saúde da população ${ }^{14}$.

No final da década de 1970, Gentile se apresentava como um crítico implacável do arranjo político dicotômico da saúde, com a divisão de atribuições entre Ministério da Saúde (MS) e Instituto Nacional de Assistência Médico-Previdenciária (INAMPS), denunciando o caráter privatista e altamente corruptor da política de saúde, "pois é a doença e não saúde a mercadoria que a alimenta" .

As ideias de Gentile ressoaram nos anos 1970 junto aos movimentos sociais que alimentavam o debate sobre a necessidade de uma reforma da saúde. Em 1977, o Centro Brasileiro de Estudos em Saúde (CEBES) publicou o primeiro livro da série "Saúde em Debate", com análises de Gentile realizadas entre 1962 e $1977^{15}$; anos depois publicou um segundo livro com as análises relativas aos anos de 1978 e $1979^{16}$. Para os editores, a obra de Gentile somava argumentos para a reforma da saúde ao proporcionar uma "análise da problemática da saúde do país"15 e abordar "problemas de saúde pública relacionados com a realidade social, econômica e política" ${ }^{\prime 6}$. Os escritos de Gentile ofertavam uma leitura abrangente da saúde na sua relação com os aspectos macroeconômicos e sociais da sociedade brasileira e, com isso, fortalecia o argumento da saúde como uma questão democrática, na busca de um Estado mais justo.

Sua última contribuição ao campo apresenta-se um ano após sua morte (1982) no livro $A$ medicina e a realidade brasileira ${ }^{7}$. Nessa obra, Gentile resume sua percepção sobre o processo saúde-doença e o papel do Estado, subsidiando a defesa de um conceito ampliado de saúde:

Não é a quantidade de médicos, de enfermeiros, de medicamentos, de leitos hospitalares, que determina o nivel de saúde de uma população. [...] hoje não padece dúvida: a saúde depende de como as pessoas se alimentam, como moram, em que condições trabalham, como se vestem, como se divertem. Em resumo, o nivel de saúde depende do nivel de vida. Em outras palavras, a saúde é uma decorrência do nivel de renda. ${ }^{7}$ (p.13).

Ou seja, retomava o debate sobre a relação saúde e desenvolvimento deixando explícito seu posicionamento quanto à necessidade de uma 
mudança estrutural nas condições de vida da população por meio da redistribuição de renda.

Gentile faleceu não tendo vivido as transformações iniciais do processo de universalização da saúde, mas já havia percebido que as mudanças em curso traziam riscos para o projeto de universalização se não houvesse o estabelecimento de mecanismos de controle do setor privado e uma revisão do modelo de prestação de serviços instalado. Em sua última análise sobre a implantação do Plano de Pronta Ação (PPA), iniciada em 1974, foi taxativo: "expandiu-se, rapidamente, a assistência médica previdenciária, obedecendo uma programação flexível, consagrando-se a política de privatização, de hospitalização, de especialização, com característica de uma completa irracionalidade" .

Seu olhar atento para o modelo de organização da previdência não deixava dúvidas quanto à participação do interesse do segmento privado na saúde. Num texto publicado em $1983^{17}$, Gentile, em diálogo com Hésio Cordeiro (nessa época professor do Instituto de Medicina Social da Universidade do Estado do Rio de Janeiro), alerta quanto aos riscos de se manter a saúde refém do setor privado apontando para os problemas decorrentes da lógica da medicina empresarial que, ao ser pautada na produção de lucros, subtraía tudo que poderia produzir gastos financeiros para as empresas. Para escapar desse modelo, conforme Gentile, seria preciso defender um sistema que preservasse o interesse da saúde das pessoas e não o lucro dos empresários.

A despeito do debate, o que se verificou a partir da segunda metade da década de 1980, foi a expansão gradativa da atuação do setor privado na saúde ${ }^{18}$, que ocorreu mesmo com a aprovação do Sistema Único de Saúde (SUS), na Constituição Federal de 1988. Juntamente com o SUS foi regulamentada a participação do setor privado de forma complementar ao sistema público, bem como foi garantida a livre iniciativa privada ${ }^{19}$, não enfrentando as regras que pautavam a relação entre o setor público e o privado na saúde e que definiam o modelo de organização dos serviços e sistema, bem como a prática médica. Gentile não presenciou o novo momento de expansão e transformação da medicina e da saúde a partir dos anos 1980, mas vislumbrou o que viria a se tornar o cenário da política de saúde ao se manter a aliança com o privado.

A vasta obra de Gentile, apesar de parcialmente divulgada pelo Cebes nos dois livros referidos, não foi objeto de análise pelo campo da saúde, mas tornou-se referência e inspiração para muitas pesquisas, com destaque para os estudos liderados por Hésio Cordeiro sobre a indústria da saúde ${ }^{20}$ e as empresas médicas ${ }^{21}$ e por Jaime Oliveira e Sonia Fleury sobre a Previdência Social $^{22}$, dentre outros. Em 2015, Noronha ${ }^{23}$ publicou uma importante síntese da obra do autor, sendo essa uma das poucas referências que sistematiza o pensamento de Gentile.

Como importante analista e formador de opinião no campo da saúde entre os anos 19601980, a obra de Gentile merece ser explorada. Suas contribuições extrapolam seu tempo e revelam a complexidade das relações que permeiam o campo da saúde. O objetivo central deste texto é apresentar a trajetória do pensamento deste sanitarista recuperando os argumentos-chave que contribuíram para o debate político e social da saúde entre os anos 1960 e 1980, ousando refletir sobre como algumas dessas questões ainda ecoam na discussão contemporânea. Sem a pretensão de esgotar seu pensamento, retomamos algumas de suas análises para, intencionalmente, produzir novos efeitos na leitura do campo da saúde.

A Saúde Coletiva como uma área de conhecimento que se assume politicamente interessada, costuma ser sumarizada em uma espécie de tripé, envolvendo as ciências sociais, a epidemiologia crítica e o planejamento em saúde ${ }^{24,25}$. A contribuição de Gentile assenta-se predominantemente nesta terceira área e voltar à sua obra é tanto reconhecer algumas das bases que sustentam o projeto de saúde coletiva como o modo de organização das políticas de saúde no Brasil, reunindo argumentos para novas proposições e inflexões no debate contemporâneo da saúde.

\section{Percorrendo os trilhos da obra}

Analista incansável das políticas de saúde e da assistência hospitalar Gentile trouxe contribuições diretas para o desenvolvimento do planejamento em saúde ${ }^{5}$. Em pouco mais de duas décadas (1960-1982), escreveu material para mais de 150 artigos em revistas científicas, mais de 300 artigos em jornais e 4 livros $^{6}$. Foi importante orador em muitos encontros, seminários e eventos da área médica e de saúde, vocalizando suas ideias e críticas à organização da saúde no Brasil e ao modelo de prestação de serviços.

Iniciou sua trajetória de escritor e analista da saúde no início dos anos 1960 abordando temas de interesse mais imediato de médicos e administradores da saúde. Seus textos foram divulgados num primeiro momento em revistas do circuito sanitarista, como: Revista de Divulgação e Infor- 
mação da Superintendência de Campanhas de Saúde Pública, Revista de Malariologia e Doenças Tropicais, Revista do Instituto de Resseguros do Brasil, e algumas revistas da área estritamente médica, como Tribuna Médica, A Folha Médica e A Patologia Geral. A partir do final dos anos 1960, e especialmente a partir da segunda metade dos anos 1970, divulgará suas análises em jornais de grande circulação como Tribuna da Imprensa e Folha de São Paulo.

Em 1962, Gentile realiza no Instituto Superior de Estudos Brasileiros (ISEB), um dos centros mais importantes de elaboração teórica do projeto "nacional-desenvolvimentista" no país ${ }^{26}$, o estudo "Saúde e Desenvolvimento Econômi-

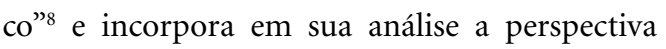
desenvolvimentista, reconhecendo as conexões entre saúde, economia, sociedade e Estado. O estudo foi divulgado e retrabalhado em diferentes veículos - revistas especializadas e imprensa - e desdobrou-se em outras análises abrindo um canal de diálogo com variadas áreas.

No estudo, Gentile busca referências históricas para compreender a atuação dos Estados na saúde das populações, reúne informações sobre a situação de saúde e a organização de serviços e estabelece comparações com outros países. Suas conclusões remetem às condições e opções dos países subdesenvolvidos na produção de saúde, trazendo para a pauta setorial o debate político em torno do Estado e do desenvolvimento e as implicações das políticas econômicas para as condições de vida e saúde da população, pois "sem promover o desenvolvimento econômico do país não se poderá solucionar o problema no setor específico em que atuam".

Esses argumentos eram seus pontos de partida para pensar a transformação do Sistema de Saúde e a defesa de uma política que possibilitasse a quebra do círculo vicioso da pobreza e da doença, tendo como principal estratégia o planejamento estatal, com vistas a garantir de forma eficiente a alocação dos recursos em saúde, evitando o desperdício e a duplicidade de ações ${ }^{8}$. Suas ideias aproximavam-se das teses de Mário Magalhães da Silveira, importante sanitarista que também insistia na priorização de investimentos na melhoria das condições de vida da população $0^{27,28}$.

O debate da saúde no início dos anos 1960 inseria-se num cenário de discussão maior sobre o desenvolvimentismo brasileiro ${ }^{29} \mathrm{e}$ as Reformas de Base propostas pelo governo João Goulart ${ }^{30}$. É nesse contexto que ocorre a III Conferência Nacional de Saúde (III CNS) (1963), tendo como proposta central a defesa de um plano nacional de saúde, ajustado às necessidades de saúde do povo brasileiro, combatendo doenças transmissíveis, melhorando a produtividade do sistema de proteção e recuperação da saúde e expandindo a rede de unidades locais de saúde ${ }^{31}$.

Nesse cenário, Gentile alertava para a importância de considerar as dificuldades de interiorização da medicina sem uma mudança concreta na situação econômica e social das regiões do país, pois havia um limite para atuação do médico nas localidades enquanto não existissem condições sociais nas regiões, pois "onde não há economia, não há prestação de serviços médicos" E como solução para enfrentar os problemas de saúde da população em regiões com dificuldade para inserção do profissional médico, Gentile fazia a defesa de uma prática de saúde exercida pelo que denominava "subprofissionais ou pessoal auxiliar"'32, ou seja, outros profissionais, não médicos, que seriam responsáveis pelo combate às doenças de massa, com utilização de técnicas simples: "o combate às doenças de massa, principal causa de morte nos países subdesenvolvidos, não exige instalações e equipamento de custo elevado; as técnicas são simples e o pessoal empregado nesses programas não necessita ser de alto padrão" ${ }^{\prime 2}$.

Ou seja, Gentile trazia junto com a perspectiva desenvolvimentista uma preocupação sobre as condições e o modelo para a atuação da medicina e dos médicos no sistema de saúde, reconhecendo a importância de se considerar esse profissional como ator relevante para organização dos serviços de saúde, mas ao mesmo tempo propondo alternativas para situações adversas.

O ano de 1964 foi mais um momento de ruptura na trajetória política do Estado brasileiro, com o início do governo autoritário ${ }^{30}$. Para a saúde pública significou um recuo na definição do plano nacional de saúde, tal como desenhado na IIICNS $^{1,31}$; para a medicina previdenciária constituiu o início de uma trajetória de modificações no escopo e lógica de organização do sistema e dos serviços ${ }^{33}$. Conforme Gentile ${ }^{7}$, em 1964 foi firmado pelo Instituto de Aposentadorias e Pensões dos Industriários (IAPI) o primeiro convênio com uma empresa prestadora de assistência médica aos seus empregados, terceirizando a responsabilidade pelas tarefas médico-assistenciais. A nova modalidade inaugurava o funcionamento da lógica empresarial na prestação de serviços médicos no contexto dos Institutos, iniciando uma trajetória de atuação do empresariado médico no setor público?. 
A unificação dos Institutos no ano de 1966 possibilitaria a consolidação para toda a Previdência do modelo denominado como "medicina de grupo ou grupo médico"7. Num contexto de expansão da economia (milagre econômico), incorporação de novos postos de trabalho e novos beneficiários, assistiu-se em poucos anos o crescimento vertiginoso do INPS e a medicina previdenciária tornou-se uma área de grande atratividade para o mercado da saúde ${ }^{34}$.

Desde então, Gentile passou a acompanhar de perto as mudanças introduzidas no sistema e a produzir com periodicidade artigos para divulgação na imprensa tornando-se um importante analista de conjuntura das políticas de saúde. Os principais temas abordados remetiam ao cenário de consolidação da modalidade de seguro saúde privado, com destaque para análise do "regime de livre escolha e o pagamento por unidade de serviço" ${ }^{35,36}$.

Sobre o regime de livre escolha, Gentile trazia a crítica à lógica de organização dos serviços a partir do consumo e de escolhas individualizadas seguindo a ótica do mercado. O regime consistia na oferta de uma lista de possibilidades de profissionais e serviços como opções de produtos a serem obtidos, como numa loja de conveniências. Tal lógica era o oposto de se buscar uma ação planejadora em saúde com vistas a uma utilização mais eficiente dos recursos, conforme idealizado no início dos anos 1960. Ao desprezar o planejamento como estratégia para organização dos serviços e para orientação da política de saúde, deixava-se para o mercado, com a utilização de recursos públicos, a atribuição de definir onde, como e o que investir na organização do sistema e serviços de saúde ${ }^{37}$. Ou seja, havia ficado de lado como projeto de Estado a lógica de um planejamento em saúde articulado ao planejamento estatal com vistas a orientar uma distribuição e utilização dos recursos de forma eficiente e melhor responder as necessidades e prioridades coletivas da população, abarcando desde ações preventivas como curativas.

Junto com a análise do regime de livre escolha, Gentile observou o mecanismo de pagamento por unidade de serviço (US) - pagamento por ato ou procedimento realizado - adotado a partir da implantação dos convênios. O novo mecanismo significou a incorporação de uma lógica financeira no atendimento médico, visto que cada ato passou a significar um valor. Quanto mais atos realizados, mais recursos captados, o que poderia induzir uma prática médica interessada muito mais na captação de recursos do que no cuidado prestado ao paciente. Foi nesse sentido que Gentile considerou a US um "fator incontrolável de corrupção"7,38 atendendo aos interesses do empresariado e de uma classe médica que passava a vislumbrar mais ganho.

As investidas para a privatização completa da saúde tornaram-se mais explícitas no ano de 1967, quando o então Ministro da Saúde Leonel Miranda apresentou a proposta de um novo Plano de Saúde com a perspectiva de adoção para toda população do modelo de seguro privado adotado no âmbito da Previdência. A reação ao Plano foi imediata mobilizando instituições de ensino, associações profissionais e sanitaristas. A Faculdade de Saúde Pública da Universidade de São Paulo (FSP/USP), num esforço de síntese das críticas apresentadas, publicou um editorial na Revista de Saúde Pública denunciando as intenções do novo projeto: "trata-se do estabelecimento de uma estrutura especificamente destinada a canalizar recursos do setor público para o privado" e uma lógica de "perpetuação da desigualdade regional" 39 .

Para Gentile, o Plano preconizava "a transferência de todos os serviços mantidos pelo poder público para a iniciativa privada, a institucionalização da unidade de serviço, a livre escolha e a participação do usuário no custeio dos serviços" ${ }^{40}$, o que também explicitava as intenções da nova política: "descumpria as prioridades da política nacional de saúde comprometendo os níveis de saúde da população e distanciando-se dos objetivos globais de desenvolvimento econômico" ${ }^{40}$. As críticas de Gentile foram apresentadas em audiência no Congresso Nacional e também amplamente divulgadas na mídia, o que lhe custou o emprego na Fundação Serviço Especial de Saúde Pública ${ }^{16}$. A partir de 1969 Gentile passaria a trabalhar no Hospital de Ipanema, do INAMPS, e no Hospital do Instituto Nacional do Câncer, do Ministério da Saúde, a convite de Nildo Aguiar, Diretor do Departamento de Administração Médica do INAMPS, aproximando-o ainda mais da dinâmica de organização da assistência médico-hospitalar nos dois contextos, saúde e previdência ${ }^{5,16}$.

As reações negativas, assim como os erros metodológicos contidos no $\mathrm{Plano}^{41}$, não possibilitaram sua efetivação tal como previsto, mas mesmo sem sua aplicação o que se apreende a partir das análises de Gentile é que as ideias e os mecanismos de privatização já estavam em pleno uso no modo de organização da assistência prestada pela previdência e pela saúde e que o Plano vinha selar a validação institucional de uma prá- 
tica em curso. Numa análise posterior do processo Almeida conclui: "a ideia de privatização foi levada adiante um pouco depois de forma muito mais competente, com a reforma da Previdência Social, que subsidiou de forma efetiva o real crescimento do setor privado no setor" ${ }^{\prime 4}$.

A partir da década de 1970 as análises de Gentile apresentaram-se cada vez mais contundentes e críticas ao processo de privatização. Em 1972, seis anos após o processo de unificação dos Institutos, Gentile apontava o caminho adotado pelo INPS de pulverização e dispersão dos recursos financeiros, com resultados questionáveis para o exercício profissional da medicina com "inevitável, comprovada e significativa diminuição dos padrões qualitativos"41.

Em estudos sobre a organização da prestação de serviços específicos, Gentile mostrará as relações entre os novos mecanismos adotados e o incremento de atos médicos e cirúrgicos, gerando maior demanda por serviços e atendimentos, um maior consumo de "saúde", incorrendo em iatrogenias na prática em saúde, medicalização e não necessariamente uma melhora nos perfis de saúde da população ${ }^{43}$. Com isso, denunciará a realização abusiva de procedimentos, o que denominará como "epidemia" de cesáreas ${ }^{44}$, histerectomias, apendicectomias, amidalectomias, etc, revelando o impacto do modelo de organização da assistência à saúde nos indicadores de saúde, ressaltando também os gastos perdulários do sistema $^{12,43}$.

Nesse contexto, compara os gastos da saúde pública com os da assistência médico-previdenciária e constata a diminuição gradativa de recursos para a saúde pública. Reconhece também no Ministério da Saúde a prática de privatização e privilegiamento da assistência hospitalar e denuncia a estrutura administrativa obsoleta, inoperacional e ineficiente do órgão. Será nesse contexto que passará a defender a integração das ações preventivas e curativas em um mesmo sistema, e a consolidação de uma medicina institucional, com remuneração e valorização do trabalho do médico. Como medicina institucional Gentile resumia: "um conjunto de órgãos destinados a cumprir programas de proteção e recuperação da saúde, mantidos e administrados pelo Estado, nos níveis federal, estadual e municipal, diretamente ou através de entidades autárquicas ou empresas públicas"14. Ou seja, estabelecimentos de saúde mantidos e administrados pelo Estado, com profissionais recebendo uma remuneração fixa mensal e tendo garantia de boas condições de trabalho, adequados ao exercício profissional não mercantilizado, e portanto, favorecedor de uma prática ética e responsável, dentro do espírito da coisa pública ${ }^{12}$.

Assim, o que Gentile chama de medicina institucional, passa pela construção de garantias da prevalência do interesse público estatal no planejamento e na gestão do sistema e também pelo enfrentamento da questão do modo de vinculação e gestão do processo de trabalho médico, buscando induzir uma prática mais afim com a produção de saúde. A defesa desse modelo contrapunha-se ao processo de mercantilização da medicina e rejeição da medicina privatizada, "condenando-se expressamente o regime de livre escolha e pagamento por unidade de serviço" ${ }^{2}$, porque produzia piora nos níveis de saúde e atendia somente aos interesses do capital.

Em 1974 uma nova mudança na condução política do Estado trará consequências para a trajetória das políticas de saúde ${ }^{33}$. O governo inicia um processo de distensão política com diretriz para "abertura lenta, gradual e segura"; edita o II Plano Nacional de Desenvolvimento (II PND) com ênfase na política social; e estabelece ações com vistas a alavancar as políticas sociais, como a criação do Conselho de Desenvolvimento Social (CDS) (1974), a instituição do Fundo de Apoio Social (FAS) (1974), o estabelecimento do Plano de Pronta Ação (PPA) (1974) e a proposição do Sistema Nacional de Saúde (SNS) (1975), dentre outras.

Nessas ações, assumia-se como diretriz a integração de áreas sociais e a ampliação/universalização do acesso aos serviços de saúde. Contudo, havia lógicas diferentes de organização da assistência à saúde no MS e no INPS que exigiam o debate sobre o modelo a se adotar. Gentile observa que a manutenção do modelo previdenciário baseado na livre escolha e no pagamento por US poderia levar a distorções ainda maiores para o sistema e tencionava no sentido de uma revisão maior ${ }^{45}$. Mas as mudanças não ocorreram, e o que de fato sucedeu foi a intensificação do processo de privatização com o PPA e o FAS, num aumento expressivo da produção e compra de serviços. O estudo de Braga e Paula ${ }^{34}$ resume a expansão observada por Gentile:

De 1967 a 1970 as taxas anuais de expansão do programa saúde do INPS são de 8,3\%, 45,7\% e 23,6\%, respectivamente. Nos anos 70 os dispêndios com assistência médica seguem expandindo-se a taxas elevadas, principalmente a partir de 1974 com o PPA (Plano de Pronta Ação): 10,3\% em 1972, 25,3\% em 73, 9,8\% em 74, 32,1\% em 75 e $36,2 \%$ em $76^{34}$ (p.176). 
vas. Em 1977 Gentile conclui: "a não ser que seja reformulado o Plano de Pronta Ação (PPA), a própria política do Ministério da Previdência e Assistência Social, será inútil o encaminhamento da implantação do Sistema Nacional de Saúde"12.

É nesse contexto que Gentile discute os indicadores de saúde e a piora nas condições de vida. Afinal, o ciclo de acelerado desenvolvimento econômico não havia possibilitado o desenvolvimento social. Na saúde, o modelo privatizado e a organização dicotômica tornavam-se empecilhos para o desenvolvimento ${ }^{46}$.

Gentile presenciava nesses anos a consolidação do que pouco depois seria nomeado por Cordeiro $^{21}$ como "complexo médico industrial da saúde". Suas análises mostravam a interferência das empresas médicas ${ }^{13}$ - hospitalares, indústria de equipamentos e farmacêutica - "na cura das doenças, no comportamento dos profissionais de saúde, no emprego dos recursos financeiros que a sociedade destina ao setor"'. Um processo entrelaçado com a lógica de formação médica. Assim, entre os anos 1960-1980 há um crescimento exponencial de novas escolas médicas, sendo mais da metade faculdades particulares ${ }^{7},-$ um ponto chave na consolidação da privatização. Para Gentile a mudança no sistema estava também atrelada à formação:

Enquanto o especialista for valorizado a Universidade estará sendo pressionada no sentido de preparar pessoal altamente qualificado, mas sem vinculação com a realidade nacional. E, nesse particular, a previdência social grande comprador de serviços assistenciais médicos, tem responsabilidade direta. Na medida em que prevalecer a política de privatização, privilegiando os produtores no campo da medicina de mercado, da medicina do lucro, as escolas médicas terão imensa dificuldade em reformular sua orientação. ${ }^{47}(\mathrm{~s} / \mathrm{pág}$ ).

Como saída, insiste na defesa de um sistema público e não sujeito às interferências do mercado, num sistema integrado que articulasse o conjunto de estratégias de atenção à saúde, retornando ao tema do desenvolvimento regional e da formação médica como elementos importantes para uma mudança estrutural do sistema. Nesse sentido, as análises da relação entre políticas de saúde e formação profissional é um importante ponto de convergência entre a aposta de Gentile na medicina institucional e o debate maior realizado na América Latina sobre a Medicina Social e os movimentos em busca de uma garantia do acesso a serviços de saúde. Desse modo, havia tanto a ênfase numa reforma do currículo médico, como a reformulação do modelo e lógica da prestação de cuidados em saúde. Assim, a discussão da medicina institucional servia também de base para um novo projeto para saúde em termos de planejamento.

Nesse contexto, na segunda metade da década de 1970, Gentile vive uma nova aproximação com órgãos do governo, como o Instituto de Pesquisa Econômica Aplicada (IPEA), e junto com Mário Magalhães e outros sanitaristas passa a assessorar um grupo de trabalho na elaboração do II Programa Nacional de Alimentação e Nutrição (II Pronan) e do Programa de Interiorização das Ações de Saúde e Saneamento (PIASS) ${ }^{48}$. Os dois programas caminhavam em direção oposta ao modelo de privatização em curso e recuperavam a lógica proposta no início dos anos 1960 de regionalização dos serviços e combate às desigualdades regionais. Mais adiante, Gentile colabora com as discussões do Programa de Reorientação da Assistência à Saúde no âmbito da Previdência Social do Conselho Consultivo da Administração da Saúde Previdenciária (CONASP) e, conforme Nildo Aguiar "chegou a ver senão todos, mas alguns dos seus objetivos concretizados pelo Conselho" 5 . Nas leituras mais correntes da saú$\mathrm{de}^{49}$, esses programas têm sido apontados como precursores do SUS. Note-se que Gentile deve ser visto não como um estudioso da história da saúde coletiva, mas certamente como um construtor dela - um construtor ativo em um momento em que o próprio entendimento de saúde coletiva e o movimento sanitário estão em processo de formação. Nessa medida, Gentile foi inspirador para aqueles que se preocupavam diretamente com a construção de um novo sistema. Preocupação que ganhava, cada vez mais, novos canais de reflexão e verbalização, como por exemplo a Associação Brasileira de Saúde Coletiva (Abrasco), fundada em 1979.

No final da década de 1970, o debate em torno da universalização do acesso aos serviços de saúde e da garantia do direito integral à saúde ganha expressão. Cresce a movimentação política e social pressionando por mudanças na direção política do Estado e diversos movimentos sociais - de moradores, estudantes, médicos, profissio- 
nais de saúde, igrejas e outros, favorecem o debate político da saúde ${ }^{50}$. Em 1979, o Congresso Nacional realiza o I Simpósio de Saúde da Câmara dos Deputados e o CEBES traz para debate o texto "A questão democrática na área da saúde" com uma proposta de constituição de um sistema único de saúde ${ }^{51}$. Conforme Noronha, "muito das reflexões de Gentile se verão espelhadas nesse texto: as precárias condições de saúde de parte significativa da população brasileira, as relações entre desenvolvimento, democracia e saúde, a mercantilização da medicina, a iniquidade na distribuição e acessos aos recursos assistenciais, a dissociação entre as ações preventiva e de saúde pública das ações curativa e de reabilitação"23.

Gentile se apresentava não só como um interlocutor importante no debate da política de saúde, mas como um difusor de propostas objetivas para reformulação do sistema contribuindo para o projeto de reformulação da assistência previdenciária. Desde seu lugar, seus esforços se direcionaram mais enfaticamente para as estratégias e projetos de garantia do caráter público de um sistema de saúde. Sua preocupação central estava no processo de privatização na prestação de serviços e na constituição de mecanismos estatais que fossem capazes de conter tal expansão, revertendo o modelo em favor da população. Mas o cenário do início dos anos 1980 mostrava-se contraditório, ao mesmo tempo em que o debate em torno da universalização fortalecia a luta pelo direito à saúde mantinha-se em franca expansão a lógica privatista na prestação de serviços.

\section{Ecoando Gentile nos tempos de uma nova expansão}

Ao retomar a trajetória de Gentile torna-se mais compreensível o fato deste sanitarista ter se tornado popular e referência no campo da saúde e no debate da reforma sanitária. Gentile foi certamente o analista de saúde que mais divulgou suas ideias para além do âmbito acadêmico. Sua vocalização ocorreu na grande mídia e voltou-se para um público amplo. Tratou principalmente da assistência médica previdenciária, segmento de saúde que teve maior expansão na segunda metade do século e que, por isso, mobilizava questões que afetavam interesses os mais diversos. Como abordou a assistência médica previdenciária e porque teceu críticas importantes à atuação do Estado nesse âmbito, pôde protagonizar a discussão da política de saúde e da proposição da reforma sanitária dos anos 1970 na posição de aliado de quaisquer movimentos sociais da saúde (profissionais, estudantes, gestores, comunidades) ou instituições que tivessem em seu horizonte a defesa da saúde universal e integral como direito.

Mas ao tratar da universalização, Gentile era incisivo no alerta sobre a necessidade de mudanças contundentes no modelo de organização dos serviços então hegemônico. Gentile teve tempo de ver algumas movimentações políticas na direção da universalização e com algum esforço de integração - como o PPA, o SNS, etc. -, e também pôde observar como elas ainda operavam na lógica privatizante. Por isso, seus trabalhos sugeriam sempre um esforço de certa proteção e garantia do interesse público das políticas de saúde do Estado.

Talvez, por isso, o foco dos seus textos tenha recaído menos no tema da universalização ou do direito universal - que se tornariam as grandes marcas do SUS -, e mais na medicina institucional, que, em síntese era a oferta de ideia que Gentile construiu do que ele imaginava como sistema e prática médica mais imunes à sanha privatista. A ideia de medicina institucionalizada pôde entrar em aspectos mais minuciosos do sistema, muito pela profundidade da imersão de Gentile não apenas no contexto dos grandes projetos institucionais, mas também nos meandros da assistência e da administração hospitalar.

Para que se entenda como as contribuições de Gentile na construção da saúde coletiva se fazem presentes até os dias de hoje, se fizermos uma rápida passagem por alguns dos dilemas vivenciados pelo SUS a partir de sua implementação, podemos encontrar alguns pontos mobilizados por ele que atualmente aparecem como questões não equacionadas. Por exemplo, sua crítica à universalização sem alteração da lógica do modelo de pagamento por US é uma questão ainda a ser enfrentada. O SUS adotou, em 1991, como única modalidade de pagamento/financiamento, com recursos federais, das internações hospitalares, o Sistema de Autorização de Internação Hospitalar $(\mathrm{AIH})^{52}$. O sistema AIH adotou a remuneração fixa por procedimento na expectativa de substituir o pagamento por ato. Contudo, o novo sistema não foi capaz de romper com a lógica convenial e do pagamento por produção ${ }^{53}$.

A propósito, nunca foi regulamentado o artigo 35 da Lei Orgânica da Saúde ${ }^{54}$ que orienta que os recursos para a saúde deveriam ser transferidos em função do perfil epidemiológico e demográfico, capacidade instalada, do desempenho técnico, econômico e financeiro prévios, do peso da saúde no orçamento dos governos, das previsões 
de planos quinquenais de investimentos, e dos ressarcimentos entre esferas de governo - todas estas, dimensões de um planejamento adequado às especificidades econômicas e sociais regionais, questão cara a Gentile desde suas primeiras incursões no debate desenvolvimentismo e saúde.

Do mesmo modo, pouco ou nada se investiu na construção de Planos de Carreira, Cargos e Salários (PCCS). Quando Gentile se dedicou aos aspectos do vínculo e da remuneração do trabalho médico - mostrando como isso impactava no processo de trabalho -, a perversão do modelo parecia se concentrar apenas nas instituições hospitalares. A sugestão então apontada por ele compunha o escopo de uma medicina institucionalizada: a criação de uma carreira nos moldes sanitaristas, com boa remuneração. Nos dias de hoje, a submissão de unidades de saúde do SUS a contratos de gestão com Organizações Sociais e congêneres que direcionam o orçamento público, aparentemente global, para um processo de trabalho programático e traduzível em contratos com o setor privado escritos em cima de indicadores e metas específicos encontra-se pulverizado por hospitais, clínicas, laboratórios e atenção primária, e parecem ter se tornado um novo "fator incontrolável de corrupção".

Ainda como parte desse mesmo dilema, outra questão tratada por Gentile que ainda persiste é a dita falta de médicos, ou, melhor traduzindo, a dificuldade de fixação de médicos em algumas regiões. Fala-se novamente em interiorizar os médicos, mas a pauta do desenvolvimento fica à parte e as estratégias adotadas ainda carecem de reflexão. $\mathrm{O}$ debate sobre a formação médica e o diálogo com a categoria, distante da pauta políti$\mathrm{ca}$, tem tornado cada vez mais longe o alcance de uma medicina institucional, em uma lógica pública. Ao mesmo tempo, o SUS expandiu a entrada de outras profissões, e aumentaram as pautas corporativas não solucionadas.

Nos anos 2000 também assistimos o retorno da discussão do novo desenvolvimentismo e a ênfase na mobilização da saúde como alavanca potencial para o crescimento econômico e desenvolvimento do setor. Como vimos, Gentile foi precursor de uma leitura sobre o complexo econômico da saúde alertando para as interferências das empresas médicas na definição de prioridades e procedimentos médicos e o que geravam de resultados para a saúde da população, indicando que nem sempre atendiam aos interesses dos usuários - por conta da iatrogenia e outras distorções da medicalização - ou dos interesses do sistema de saúde - por conta da irracionalidade dos gastos ${ }^{7}$. Nesse sentido, para Gentile o consumo em saúde mobilizado pelo complexo da saúde não deveria ser tratado como alavanca potencial para o crescimento econômico e desenvolvimento do setor sem se observar as consequências para a vida e o bem-estar da população, devendo ser orientado por um planejamento estatal. Nos anos 2000, talvez sejam necessários novos estudos, inspirados naqueles realizados por Gentile, para aprofundar as relações entre prestadores e Estado, a duplicidade de ações, os vazios assistenciais e as iatrogenias. Mas estudos como esses, agora terão que enfrentar o aumento da fragmentação institucional imposta pela pulverização de instituições privadas envolvidas na gestão dos serviços do SUS, inclusive na atenção básica - cuja extensão não foi vivida por Gentile. Em suma, os termos da disputa são outros, mas a preocupação fundamental de Gentile ainda pode ser evocada: o papel e o funcionamento do Estado na luta pela saúde pública como direito.

Ou seja, retomar o discurso de Gentile mostra agendas não encaminhadas, esvaziadas e acirradas. Mas como os problemas, e as críticas, nunca são mera repetição do passado, aquilo que permaneceu não equacionado foi se transformando ao mesmo tempo em que permitiu a construção do SUS. Assim, ao mesmo tempo em que o SUS trilhou o caminho da universalidade do direito à saúde ocorreu a ampliação das entradas do mercado privado de saúde por dentro do público.

Com as críticas em torno da privatização da saúde e do papel do Estado no desenvolvimento, Gentile deu sua contribuição no campo da economia da saúde, mas também esteve atento ao campo da prática médica, chamando atenção para a iatrogenia produzida pelo uso indiscriminado de procedimentos, distante de uma racionalidade clínica, e ao campo da formação médica, quando ressalta que este é um aspecto estrutural do sistema.

Assim, Gentile colocava a discussão em outro patamar, ajudando também a entender os diferentes caminhos políticos na área da saúde, o que contribuiu para o reconhecimento dos diferentes atores e interesses no jogo político que se estenderia dos anos 1970 em diante.

Por tudo isso, revisitar Carlos Gentile de Mello é também de certa forma reconhecer que suas críticas além de coerentes e necessárias ao seu tempo permanecem como questões referidas à institucionalidade da área da saúde, que precisam ser recolocadas no debate de hoje. 


\section{Colaboradores}

TWF Baptista e CF Borges trabalharam igualmente na concepção, redação e revisão final do manuscrito.

\section{Referências}

1. Teixeira SMF, organizador. Antecedentes da Reforma Sanitária. Relatório de Pesquisa PEC/ENSP. Rio de Janeiro: Fiocruz/ENSP; 1988.

2. Costa Filho DC. A falsidade do círculo vicioso da pobreza e da doença. Saude Debate 1978; 6:65-66.

3. Pires-Alves FA, Paiva CHA, Falleiros I. Saúde e Desenvolvimento: a agenda do pós-guerra. In: Ponte CF, Falleiros I. Na corda bamba de sombrinha: a saúde no fio da história. Rio de Janeiro: Fiocruz/COC, Fiocruz/ EPSJV: 2010. p.153-180.

4. Nunes ED. Saúde Coletiva: revisitando sua história e os cursos de pós-graduação. Cien Saude Colet 1996; 1(1):55-69.

5. Aguiar NEA. Prefácio. In: Mello CG. A Medicina e a realidade brasileira. Rio de Janeiro: Achiamé; 1983.

6. Casa de Oswaldo Cruz. Fundo GM - Carlos Gentile de Mello [Internet]. [acessado 2019 maio 13]. Disponível em: http://icaatom.coc.fiocruz.br/index.php/carlosgentile-de-carvalho-mello.

7. Mello CG. A medicina e a realidade brasileira. Rio de Janeiro: Achiamé; 1983.

8. Mello CG. Saúde e Desenvolvimento Econômico [monografia]. Rio de Janeiro: Instituto Superior de Estudos Brasileiros; 1962.

9. Mello CG. Implicações sociais da livre escolha. Diário Médico, Diário de Notícias; 1967.

10. Mello CG. O controle do regime de livre escolha. Diário Médico, Diário de Notícias; 1968.

11. Mello CG. Medicina, quando o lucro é a pesquisa. Politika 1973; II(84): Sessão Denúncia.

12. Mello CG. A irracionalidade da privatização da medicina previdenciária. Saude Debate 1977; 3:8-15.

13. Mello CG. A Saúde? Onde fica a saúde? Folha de São Paulo; 1977.

14. Mello CG. A mercantilização da medicina. A Patologia Geral; 1973.

15. Mello CG. Saúde e Assistência Médica no Brasil. São Paulo: Cebes/Hucitec; 1977.

16. Mello CG. O sistema de saúde em crise. São Paulo: Cebes/Hucitec; 1981

17. Cordeiro H. A medicina de grupo e o complexo médico-industrial. Rev Adm Publica 1983; 17(3):22-37.

18. Bahia L, Scheffer M. O SUS e o setor privado assistencial: interpretações e fatos. Rev Saude Debate 2018; 42(3):158-171.

19. Brasil. Constituição da República Federativa do Brasil de 1988. Diário Oficial da União 1988; 5 out.

20. Cordeiro H. A Indústria de saúde no Brasil. Rio de Janeiro: Graal; 1980.

21. Cordeiro H. As empresas médicas. Rio de Janeiro: Graal; 1984.

22. Oliveira JAA, Teixeira SMF. (IM)Previdencia Social: 60 anos de história da previdência no Brasil. Petrópolis: Vozes; 1986.

23. Noronha JC. Carlos Gentile de Mello: desenvolvimento é saúde, saúde não é mercadoria. In: Hochman G, Lima NT, organizadores. Médicos e intérpretes do Brasil. São Paulo: Ed.Hucitec; 2015. p. 552-571.

24. Nunes ED. Saúde coletiva: história de uma ideia e de um conceito. Saude Soc 1994; 3(2):5-21. 
25. Paim JS, Almeida Filho N. Saúde coletiva: uma "nova saúde pública" ou campo aberto a novos paradigmas? Rev Saude Publica 1998; 32(4):299-316.

26. Fundação Getúlio Vargas (FGV). Centro de Pesquisa e Documentação de História Contemporânea do Brasil (CPDOC). O ISEB e o desenvolvimentismo [Internet]. [acessado 2019 jun 25]. Disponível em: http://cpdoc. fgv.br/producao/dossies/JK/artigos/Economia/ISEB.

27. Escorel S. Mário Magalhães: Desenvolvimento é saúde. Cien Saude Colet 2015; 20(8):2453-2460.

28. Reis JRF. Viver é influenciar? Mário Magalhães, sanitarismo desenvolvimentista e o campo intelectual da saúde pública (1940-1960). Tempo Soc 2015; 27:279304.

29. Lima NT, Fonseca CMO, Hochman G. A saúde na construção do Estado Nacional no Brasil: reforma sanitária em perspectiva histórica. In: Lima NT, Gerschman S, Edler FC organizadores. Saúde e Democracia: história e perspectivas do SUS. Rio de Janeiro: Ed. Fiocruz; 2005. p. 27-58.

30. Toledo CN. 1964: o golpe contra as reformas e a democracia. Rev Bras Hist 2004; 24(47):13-28.

31. Brasil. Ministério da Saúde (MS). Relatório da III Conferência Nacional de Saúde. Brasília: MS; 1963.

32. Mello CG. Assistência Médica e Desenvolvimento Econômico. Rev Bras Malariologia Doenças Tropicais 1963; 15(2):291-297.

33. Paiva CHA, Teixeira LA. Reforma sanitária e a criação do Sistema Único de Saúde: notas sobre contextos e autores. Hist Cien Saude Manguinhos 2014; 21(1):1536.

34. Braga JCS, Paula SG. Saúde e Previdência. Estudos de política social. São Paulo: Editora Hucitec; 2018.

35. Mello CG. Implicações sociais da livre escolha. Diário Médico, Diário de Notícias; 1967.

36. Mello CG. O controle do regime de livre escolha. Diário Médico, Diário de Notícias; 1968.

37. Mello CG. A produtividade do setor saúde. Análises e Perspectivas Econômicas; 1966.

38. Mello CG. A remuneração médica e os programas de saúde. Rev Bras Malariologia Doenças Tropicais 1969; 21(3):627-633.

39. Apreciação do "Plano Nacional de Saúde". Rev Saude Publica 1968; 2(2):95-110.

40. Mello CG. Análise do Plano Nacional de Saúde. A Patologia Geral 1968; XIII(11/12):139-149.

41. Mello CG. As implicações sociais e econômicas dos convênios do INPS. Tribuna da Imprensa 1972; 5/6.

42. Almeida C. Comentário: política e planejamento: o Plano de Saúde Leonel Miranda. Rev Saude Publica 2006; 40(3):381-385.

43. Mello CG. Frutos da permissividade. Folha de São Paulo; 1978.

44. Mello CG. A Epidemiologia da Cesariana. Semana Med 1971; ano XI: 591.

45. Mello CG. O Sistema Nacional de Saúde. Proposições e perspectivas. Rev Saude Debate 1976; 1:23-25.

46. Mello CG. Desenvolvimento social. Folha de São Paulo; 1977.

47. Mello CG. Médicos generalistas. Folha de São Paulo; 1976.
48. Escorel S. Saúde Pública. Rio de Janeiro: Relume-Dumará; 2000.

49. Escorel S, Nascimento DR, Edler F. As origens da Reforma Sanitária e do SUS. In: Lima NT, organizador. Saúde e Democracia: história e perspectivas do SUS. Rio de Janeiro: Ed. Fiocruz; 2005.

50. Gerschman S. A democracia inconclusa. Rio de Janeiro: Ed. Fiocruz; 2004.

51. Centro Brasileiro de Estudos de Saúde (Cebes). A questão democrática na área da saúde. Rev Saude Debate 1980; 9:13-15.

52. Levcovitz E, Pereira TRC. SIH/SUS (Sistema AIH): uma análise do sistema público de remuneração de internações hospitalares no Brasil 1983-1991. Rio de Janeiro: UERJ/IMS; 1993.

53. Centro Brasileiro de Estudos de Saúde (Cebes). Para onde vai o dinheiro do SUS? Rev Saude Debate 1991; 31:88.

54. Piola SF, Paiva AB, Sá EB, Servo LMS. Financiamento público da saúde: Uma história à procura de rumo. Texto para Discussão. Brasília: IPEA; 2013.
Artigo apresentado em 01/07/2019

Aprovado em 02/12/2019

Versão final apresentada em 04/12/2019

Editores-chefes: Romeu Gomes, Antônio Augusto Moura da Silva 
